Article

\title{
Controllable Carbonization of Plastic Waste into Three-Dimensional Porous Carbon Nanosheets by Combined Catalyst for High Performance Capacitor
}

\author{
Xueying $\mathrm{Mu}^{1,2}$, Yunhui $\mathrm{Li}^{1, *}$, Xiaoguang Liu ${ }^{3}$, Changde $\mathrm{Ma}^{2}$, Hanqing Jiang ${ }^{2}$, Jiayi Zhu ${ }^{4}$, \\ Xuecheng Chen ${ }^{3, *} \mathbb{D}$, Tao Tang ${ }^{2, *}$ and Ewa Mijowska ${ }^{3}[$ \\ 1 School of Chemistry and Environmental Engineering, Changchun University of Science and Technology, \\ Changchun 130022, China; xymu@ciac.ac.cn \\ 2 State Key Laboratory of Polymer Physics and Chemistry, Changchun Institute of Applied Chemistry, \\ Chinese Academy of Sciences, Changchun 130022, China; cdma@ciac.ac.cn (C.M.); hqjiang@ciac.ac.cn (H.J.) \\ 3 Faculty of Chemical Technology and Engineering, West Pomeranian University of Technology, Piastow Ave. \\ 42, 71-065 Szczecin, Poland; Xiaoguang.Liu@zut.edu.pl (X.L.); emijowska@zut.edu.pl (E.M.) \\ 4 State Key Laboratory of Environment-friendly Energy Materials, School of Science, Southwest University of \\ Science and Technology, Mianyang 621010, China; jyzhu@swust.edu.cn \\ * Correspondence: liyh@cust.edu.cn (Y.L.); xchen@zut.edu.pl (X.C.); ttang@ciac.ac.cn (T.T.); \\ Tel.: +86-431-8558-2361 (Y.L.); +48-091-449-6030 (X.C.); +86-431-8526-2004 (T.T.)
}

Received: 11 May 2020; Accepted: 30 May 2020; Published: 2 June 2020

\begin{abstract}
Polyethylene terephthalate (PET) plastic has been extensively used in our social life, but its poor biodegradability has led to serious environmental pollution and aroused worldwide concern. Up to now, various strategies have been proposed to address the issue, yet such strategies remain seriously impeded by many obstacles. Herein, waste PET plastic was selectively carbonized into three-dimensional (3D) porous carbon nanosheets (PCS) with high yield of $36.4 \mathrm{wt} \%$, to be further hybridized with $\mathrm{MnO}_{2}$ nanoflakes to form PCS-MnO 2 composites. Due to the introduction of an appropriate amount of $\mathrm{MnO}_{2}$ nanoflakes, the resulting PCS- $\mathrm{MnO}_{2}$ composite exhibited a specific capacitance of $210.5 \mathrm{~F} \mathrm{~g}^{-1}$ as well as a high areal capacitance of $0.33 \mathrm{~F} \mathrm{~m}^{-2}$. Furthermore, the PCS- $\mathrm{MnO}_{2}$ composite also showed excellent cycle stability $(90.1 \%$ capacitance retention over 5000 cycles under a current density of $10 \mathrm{~A} \mathrm{~g}^{-1}$ ). The present study paved an avenue for the highly efficient recycling of PET waste into high value-added products (PCSs) for electrochemical energy storage.
\end{abstract}

Keywords: PET; waste plastic; carbonization; energy storage

\section{Introduction}

Due to its light weight and outstanding mechanical properties, plastic has been widely used in many fields. However, with the ever-increasing consumption of plastic products, it has flooded almost every corner of peoples' lives, and its poor biodegradability has resulted in serious environment pollution [1,2]. Currently, landfill and incineration are the most widely adopted strategies for the treatment of plastics wastes [3-5]. Nevertheless, in the long term, the decomposition of plastic waste buries underground will lead to soil and underground water contamination and harmful gases will be released into the air. However, the inappropriate treatment of plastic waste will not only cause resource waste, but also induce serious environmental pollution [6]. Although many strategies have been proposed to treat and reuse the plastic waste, it is still a great challenge to recycle the plastic waste at large scale [7]. Among various commonly used plastics, polyethylene terephthalate (PET) is widely used in our social life. For example, in China, all plastic bottles are made from PET and up to 3 million tons of PET plastic bottles are consumed every year. Therefore, developing a method for 
efficient recycling of PET waste plastics has a significant impact on resources and the environment. Considering the high carbon content of PET (62.5 wt\%), the transformation of PET waste into carbon materials is regarded as one of the most potentially beneficial methods due to the wide applications of carbon materials in various research fields [8]. However, the native low carbonization yield of PET seriously prohibits the implementation of this strategy as only $20 \mathrm{wt} \%$ of carbon material can be recycled. This is much lower than expected. Therefore, it is still a challenge to efficiently carbonize PET with high yield [9]. More importantly, it is hard to achieve controllable carbonization of PET into pre-designed nanostructures with determined physical and chemical properties [10,11].

Up to now, many research works have been published on recycling of PET waste [12-15]. For example, Elessawy et al. mixed PET waste with urea to react in autoclave reactor to prepare 3D sponge nitrogen-doped graphene [16]. The prepared N-doped graphene shows excellent specific capacitance and energy density. Kamali et al. mixed PET with $\mathrm{NaCl}$ with subsequent heat treatment, in which molten salt acted as a graphitization medium to improve the quality of PET plastic-derived carbon [17]. As an important energy storage device, the supercapacitor has drawn huge attention in the scientific community due to its high power density, long cycle life, and wide operating temperature range [18-20]. Although many achievements have been made, the carbonization yield is still much lower than expected. As the most essential component of the supercapacitor, the electrode material mainly determines the electrochemical performance, the exploitation of new advanced electrode materials has become the research hotspot in recent years. In general, electrode materials can be divided into three categories: carbon materials, metal oxides, and polymers [21]. Because of the excellent thermal/chemical stability, excellent conductivity, and tunable surface area, carbon materials are the most extensively studied electrode materials so far [22-25]. According to the molecular structure, the carbon content of waste PET plastic is as high as $62.5 \mathrm{wt} \%$. Therefore, it is highly desired to transform PET waste into a carbon material for electrodes, which will not only reduce the environmental burden, but also provide advanced electrode materials for energy storage. It is of considerable significance to develop an efficient, time-saving, and cost-effective strategy to recycle PET waste, and more importantly, achieving controllable and high yield carbonization of PET waste simultaneously.

According to previous research, it is feasible that $\mathrm{MgO}$ can be used as a hard template to prepare two-dimensional carbon nanosheets, but stacking is likely to occur between carbon flakes due to $\pi-\pi$ interaction. When cobalt acetylacetonate (III) $\left(\mathrm{Co}(\mathrm{acac})_{3}\right)$ is fully mixed with $\mathrm{MgO}$ flakes to form a hybrid catalyst, the resulting three-dimensional structure will not only stop the re-stacking of carbon nanosheets, but also facilitate the ion transportation within the carbon framework and further improve capacitor performance. In this contribution, waste PET bottles were used as carbon source, the hybrid $\mathrm{MgO} / \mathrm{Co}(\text { acac })_{3}$ was used as a combined catalyst, and the porous carbon nanosheets (PCS) were selectively prepared by catalytic carbonization of PET waste. The yield of PCS was up to $36.4 \mathrm{wt} \%$, which is much higher than that of neat PET carbonization product (CP) yield of $22 \mathrm{wt} \%$, demonstrating the high catalytic activity of the prepared combined catalyst. $\mathrm{MnO}_{2}$ nanoflakes were further loaded on the resulting PCSs by redox reaction to obtain hybrid PCS- $\mathrm{MnO}_{2}$ composite, which introduced the pseudo-capacitance and further improved the capacitive performance of the hybrid material. More importantly, the PCS- $\mathrm{MnO}_{2}$ showed an ultrahigh areal capacitance of $0.33 \mathrm{~F} \mathrm{~m}^{-2}$, as well as long cycle stability [26].

\section{Materials and Methods}

\subsection{Materials}

$\mathrm{MgO}$ was purchased from China Guangdong Xilong Science Co., Ltd., and Co(acac) 3 (98\%) was obtained from Aladdin Biochemical Technology Co., Ltd. (Shanghai, China). $\mathrm{KMnO}_{4}$ was purchased from Beijing Chemical Plant (Beijing, China). The waste PET plastic used was a recycled waste plastic bottle. Anhydrous ethanol and $\mathrm{HCl}$ acid were purchased from Beijing Chemical Plant (Beijing, China), without any further purification. 


\subsection{Preparation of Porous Carbon Nanosheet (PCS)}

Neat PET carbonization product (CP) was obtained by direct carbonization of waste PET in a reaction kettle at $700{ }^{\circ} \mathrm{C}$. For the preparation of PCS, in the typical synthesis, $\mathrm{MgO}$ and $\mathrm{Co}(\mathrm{acac})_{3}$ were put into a ball mill with a mass ratio of 2:1 to get a combined catalyst $\left(\mathrm{MgO} / \mathrm{Co}(\mathrm{acac})_{3}\right)$. The waste PET was firstly cut into small fragments and mixed with the combined catalyst at a mass ratio of 1:2, followed by introducing into an autoclave to react at $700{ }^{\circ} \mathrm{C}$ for $1 \mathrm{~h}$. Subsequently, the carbon product was taken out and refluxed in $1 \mathrm{M} \mathrm{HCl}$ acid solution at $100{ }^{\circ} \mathrm{C}$ for $12 \mathrm{~h}$ to remove $\mathrm{MgO}$ and cobalt oxide from the carbon sample. In the next step, the mixture was filtered to get the PCSs sample. Finally, the PCSs were dried in vacuum at $80^{\circ} \mathrm{C}$ prior to the electrochemical test.

\subsection{Preparation of Porous Carbon Nanosheet (PCS- $\left.\mathrm{MnO}_{2}\right)$}

To load $\mathrm{MnO}_{2}$ nanoflakes on PCSs, in a typical synthesis, $25 x \mathrm{mg}(x=1,2,4)$ of $\mathrm{KMnO}_{4}$ was dissolved in $500 \mathrm{~mL}$ deionized water, and the solution was heated at $80{ }^{\circ} \mathrm{C}$ in an oil bath. Then $100 \mathrm{mg}$ of the as-prepared carbon material (PCS) was added and stirred gently for $1 \mathrm{~h}$. After cooling to room temperature, the PCS-MnO 2 composite was separated from the mixture and dried in vacuum for further use. The final composite product was denoted as $\mathrm{PCS}-\mathrm{MnO}_{2}-x(x=1,2,4)$.

\subsection{Characterization}

The morphology of the carbon nanomaterial was measured by a field emission scanning electron microscope (SEM, XL30ESEM-FEG) of Japan JEOL Company at an acceleration voltage of $20 \mathrm{kV}$, and the microscopic structure of the carbon nanomaterial was tested by a transmission electron microscope (TEM, JEM-1011) of Japan JEOL Company at an acceleration voltage of $100 \mathrm{kV}$. The phase composition of the carbon nanomaterial was determined by X-ray diffraction (XRD, D8 Advance X-ray diffractometer) of German Bruker Company, and the purity and thermal stability of carbon material was analyzed by a thermogravimetric analyzer (TA Instruments SDT Q600) of American TA company. The elemental composition and contents of the materials were determined by X-ray photoelectron spectroscopy (VG

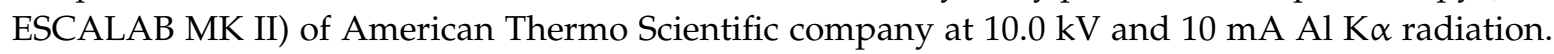
The $\mathrm{N}_{2}$ adsorption/desorption isotherms were obtained at liquid nitrogen temperature $(77 \mathrm{~K})$ on the Micromeritics ASAP 2010 M of American Micromeritics company. The density functional theory (DFT) and Brunauer-Emmett-Teller (BET) methods were used to calculate the specific surface area and pore size distribution.

\subsection{Electrochemical Test}

To prepare the working electrode, in a typical synthesis, the active material, conductive carbon black, and $5 \mathrm{wt} \%$ of polytetrafluoroethylene (PTFE) solution were mixed together to form a paste with a mass ratio of $8: 1: 1$, then the paste was uniformly coated on nickel foam (area: $1 \mathrm{~cm}^{2}$ ), the loading amount of the active material of the obtained electrode was approximately $4 \mathrm{mg} \mathrm{cm}^{-2}$. And then placed in a vacuum drying oven at $80{ }^{\circ} \mathrm{C}$ for $12 \mathrm{~h}$. Then, a roller press was applied to press the electrode sheet to a thickness of $0.5 \mathrm{~mm}$. A platinum plate was used as a counter electrode for a three-electrode test system, and $6 \mathrm{~mol} \mathrm{~L}^{-1}$ of $\mathrm{KOH}$ was used as the electrolyte. After the electrode sheet was soaked in the electrolyte for $12 \mathrm{~h}$, the electrochemical tests were carried out on the electrochemical workstation (CHI 660E). Cyclic voltammetry (CV) was tested at a voltage window of $-1 \sim 0 \mathrm{~V}$ with a scan rate of $1 \sim 200 \mathrm{mV} \mathrm{s}^{-1}$. The galvanostatic charge-discharge (GCD) test was carried out under the test voltage window of $-1 \sim 0 \mathrm{~V}$ and with a current density of $0.5 \sim 20 \mathrm{~A} \mathrm{~g}^{-1}$. The electrochemical impedance test is in range of $0.01 \mathrm{~Hz} \sim 100 \mathrm{kHz}$. In the three-electrode system, the gravimetric specific capacitance and the areal specific capacitance is calculated from the following equations:

$$
C_{w t(C V)}=\frac{1}{2 m s\left(V_{b}-V_{a}\right)} \int_{v_{a}}^{v_{b}} I d V
$$




$$
\begin{aligned}
C_{w t(G C D)} & =\frac{I * \Delta t}{m\left(V_{b}-V_{a}\right)} \\
C_{\text {areal }} & =\frac{C_{w t(C V)}}{S_{B E T}}
\end{aligned}
$$

where $C_{w t(G C D)}\left(\mathrm{F} \mathrm{g}^{-1}\right)$ and $C_{w t(C V)}\left(\mathrm{F} \mathrm{g}^{-1}\right)$ are the gravimetric specific capacitance $(C)$ calculated from GCD and CV results, $I$ (A) is the current response, $V_{b}$ and $V_{a}$ are the high and low potential limits, $m$ represents the carbon material mass, $s\left(\mathrm{mV} \mathrm{s}^{-1}\right)$ is the scanning rate, and $C_{\text {areal }}\left(\mathrm{F} \mathrm{m}^{-2}\right)$ is the areal specific capacitance, which is obtained by dividing the gravimetric specific capacitance by the specific surface area of carbon. $S_{B E T}\left(\mathrm{~m}^{2} \mathrm{~g}^{-1}\right)$ is the specific surface area calculated from the $\mathrm{N}_{2}$ adsorption and desorption $(77 \mathrm{~K})$ isotherm.

\section{Results}

The synthetic route for the preparation of PCS- $\mathrm{MnO}_{2}$ composites is presented in Figure 1a. At the elevated temperature to $700{ }^{\circ} \mathrm{C}$ in the reactor, PET firstly decomposed into small organic molecules such as methane, ethylene, and other aromatic hydrocarbons [27]. At the same time, CoO nanoparticles were formed by the decomposition of $\mathrm{Co}(\mathrm{acac})_{3}$ and distributed on $\mathrm{MgO}$ flakes evenly. Based on the decomposition-diffusion-precipitation mechanism [28], the produced small organic molecules began to deposit on the surface of $\mathrm{CoO} / \mathrm{MgO}$ undergoing a dehydrogenation and aromatization reaction to form carbon layer coated on $\mathrm{CoO} / \mathrm{MgO}$ [29]. After the removal of $\mathrm{MgO}$ and cobalt oxide species, the PCSs were finally obtained. Notably, these curved carbon nanosheets can effectively prevent carbon sheets from re-stacking process. $\mathrm{MnO}_{2}$ nanoflakes were subsequently deposited on PCSs through the redox reaction to form PCS- $\mathrm{MnO}_{2}$ composite [30]. The corresponding chemical reaction is shown below [31]:

$$
4 \mathrm{MnO}_{4}{ }^{-}+3 \mathrm{C}+3 \mathrm{H}_{2} \mathrm{O} \rightarrow 4 \mathrm{MnO}_{2}+\mathrm{CO}_{3}{ }^{2-}+2 \mathrm{HCO}_{3}{ }^{-}
$$

The SEM and TEM were measured to investigate the microstructure of the obtained samples at different stages. Figure 1b, f presents the TEM and SEM images of the prepared PCS. They reveal a 3D structured porous carbon sheet with a thickness of ca. $20 \mathrm{~nm}$. Figure 1c-e exhibit TEM images of PCS-MnO ${ }_{2}$ hybrid composite. It is easy to observe that the morphology of the PCS- $\mathrm{MnO}_{2}$ composite are the flake $\mathrm{MnO}_{2}$ with a diameter of ca. $15 \mathrm{~nm}$ attached to the surface of the PCS. With the increase of the amount of $\mathrm{KMnO}_{4}$ added, the amount of flake $\mathrm{MnO}_{2}$ loaded on the PCS surface gradually enhanced from PCS- $\mathrm{MnO}_{2}-1$ to $\mathrm{PCS}-\mathrm{MnO}_{2}-4$, and the thickness of $\mathrm{MnO}_{2}$ also increased slightly. Figure $1 \mathrm{~g}$ shows the SEM image of PCS- $\mathrm{MnO}_{2}-2$ with the inset revealing $\mathrm{MnO}_{2}$ nanoflakes as indicated by red circle.

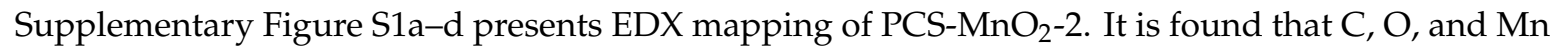
elements are evenly distributed in the measured sample.

Catalytic efficiency is one of the most important parameters to influence the applicability of the tested catalyst for carbonization of plastic waste. The obtained carbon product fabricated without adding any catalyst is in the form of carbon block (Figure 2a). The carbonization yield of this sample is only $22 \mathrm{wt} \%$ (see Figure 2d). When PET waste was mixed with MgO flakes, the carbonization yield increased to $25.1 \mathrm{wt} \%$, slightly higher than PET itself. The morphology of this sample was in the form of flake structured carbon derivated from $\mathrm{MgO}$ template (Figure $2 \mathrm{~b}$ ). When only $\mathrm{Co}(\mathrm{acac})_{3}$ was introduced to PET waste, the carbonization yield increased to $26 \mathrm{wt} \%$, demonstrating slightly higher catalytic activity of $\mathrm{Co}(\mathrm{acac})_{3}$ than $\mathrm{MgO}$ and PET itself. The morphology of this sample is depicted in Figure 2c. It shows core/shell structured carbon spheres. The size of carbon spheres is in the range of 20-50 nm. However, when $\mathrm{Co}(\mathrm{acac})_{3}$ and $\mathrm{MgO}$ were introduced together to form a combined catalyst, the carbonization efficiency was dramatically enhanced to $36.4 \mathrm{wt} \%$. This is much higher than $\mathrm{MgO}$ and $\mathrm{Co}(\mathrm{acac})_{3}$ itself, further demonstrating the positive synergistic effect between $\mathrm{Co}(\mathrm{acac})_{3}$ and $\mathrm{MgO}$. The carbon product is in the form of folded flakes with rich mesopores, as shown in Figure $1 \mathrm{~b}$. 

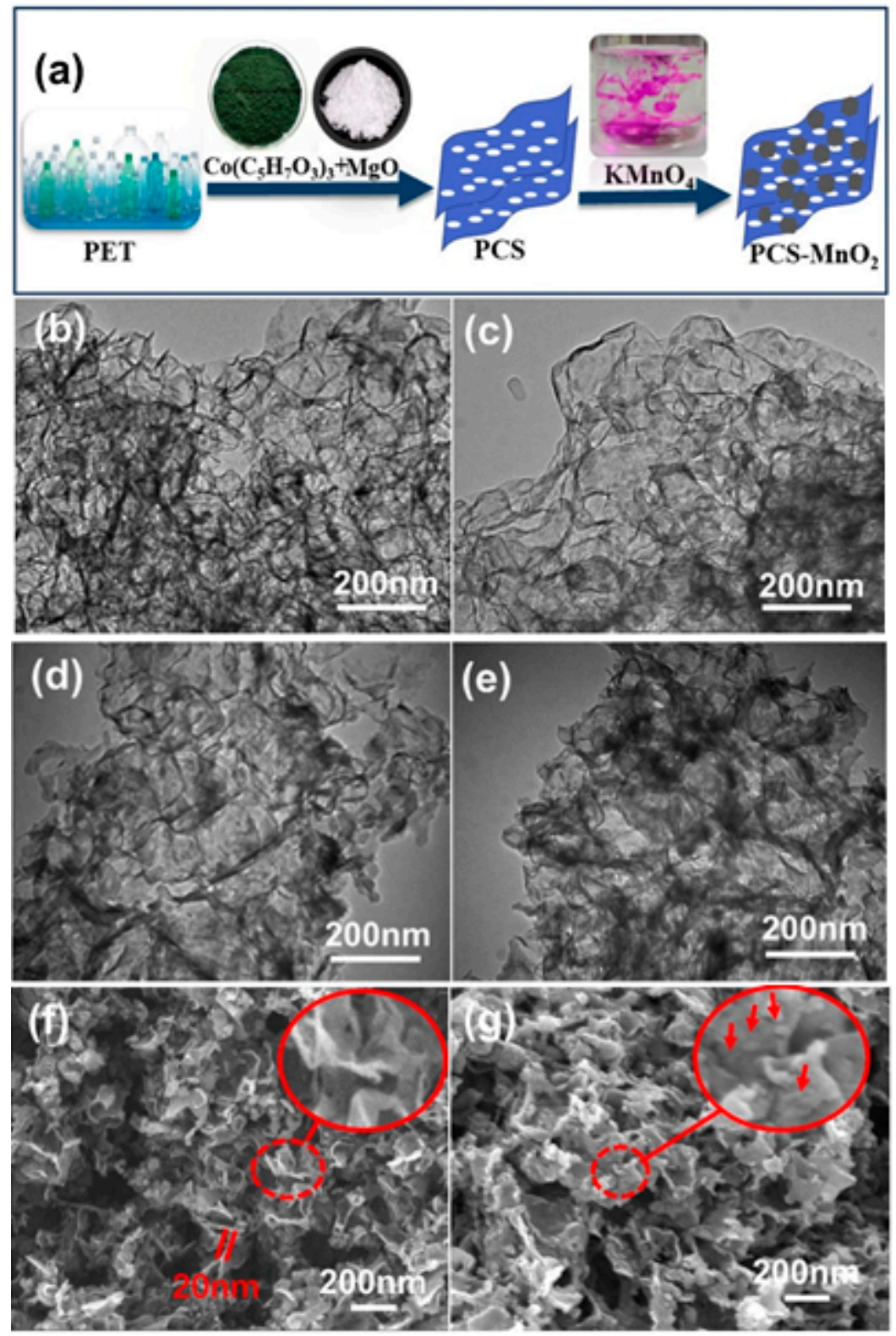

Figure 1. (a) Schematic illustration for the synthesis of PET waste derived PCS-MnO 2 . TEM images of (b) PCS (c) PCS-MnO -1 (d) PCS- $\mathrm{MnO}_{2}-2$ (e) PCS-MnO $\mathrm{Mn}_{2}-4$; SEM image of (f) PCS (g) PCS-MnO -2 .

The phase composition and crystallinity of carbon samples at different stages were determined by X-ray diffraction (XRD). As observed in Figure 3a, the typical (200) peak at $43^{\circ}$ and (220) peak at $62^{\circ}$ are assigned to $\mathrm{MgO}$ (JCPDS 77-2179), which demonstrate the existence of $\mathrm{MgO}$ template. Besides, there are typical peaks corresponding to $\mathrm{CoO}$ from decomposition of $\mathrm{Co}(\mathrm{acac})_{3}$ (JCPDS 75-0418) in the pattern. It is believed that the formed $\mathrm{CoO}$ with $\mathrm{MgO}$ synergistically promote the dehydrogenation and carbonization of the polymer when considering the carbonization yield [29,32]. In the XRD spectrum of PCS there are only two strong peaks at $26^{\circ}$ and $43^{\circ}$ corresponded to (002) and (101) crystal planes of hexagonal graphite [33]. In PCS- $\mathrm{MnO}_{2}-2$, except for the peak at $26^{\circ}$, there are typical $\delta-\mathrm{MnO}_{2}$ (JCPDS 42-1317) peaks, which have been marked in the curves, indicating the existence of $\mathrm{MnO}_{2}$ in the composite [34]. 

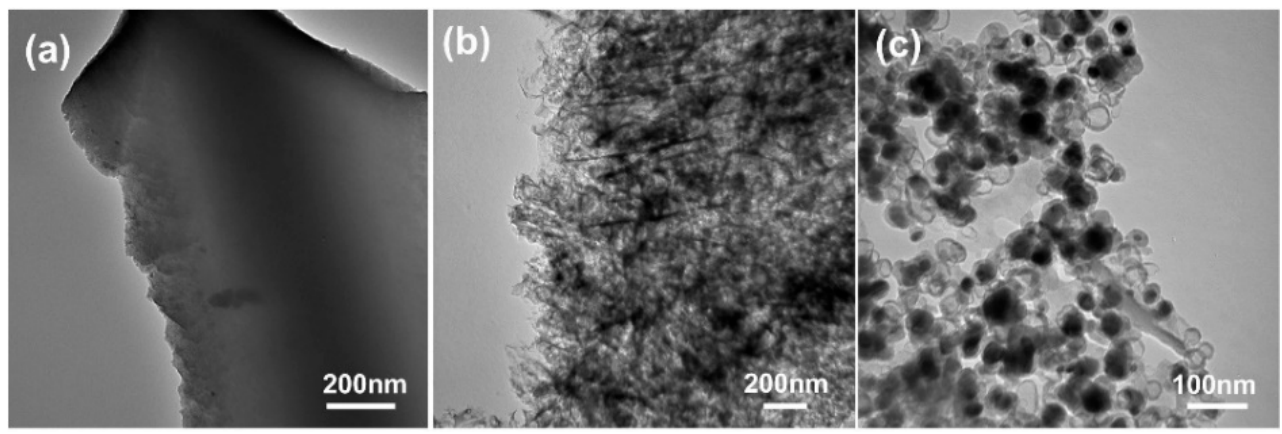

(d)

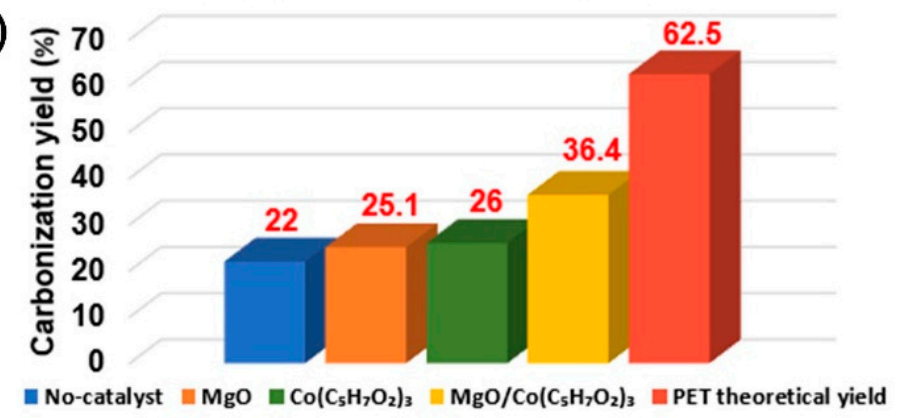

Figure 2. TEM images of (a) Carbon prodcut from neat PET, (b) Carbon sample prepared from PET/MgO, (c) Carbon sample from PET/Co(acac) 3 and (d) the corresponding carbon yields from different catalyst.

(a)

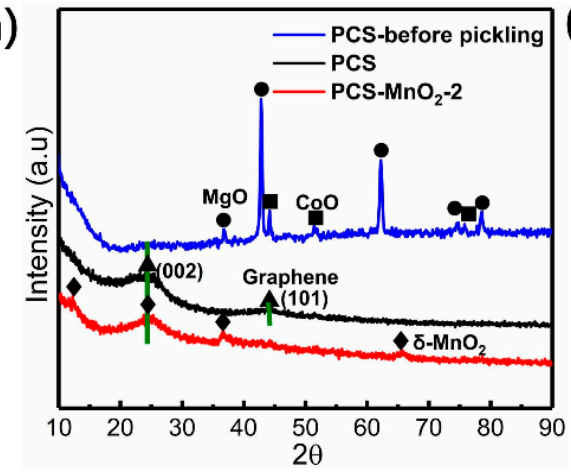

(b)

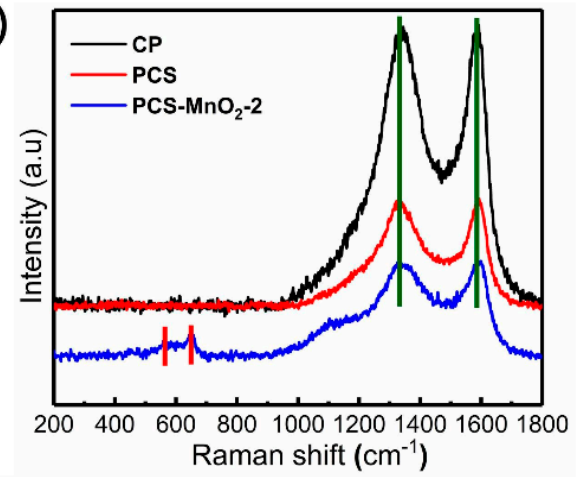

Figure 3. (a) XRD patterns of carbon product prepared from directly carbonized from $\mathrm{Co}(\mathrm{acac})_{3} / \mathrm{MgO} / \mathrm{PET}$ composite, PCS and PCS-MnO $2-2$. (b) Raman spectra of CP, PCS and PCS-MnO -2 .

TGA was carried out to determine the carbon content of the tested samples. All of the materials were tested under air atmosphere. As shown in Supplementary Figure S2, the amount of residual carbonized initial product is $74.4 \%$, which indicates the amount of catalyst in the carbonized product. At $800^{\circ} \mathrm{C}$, the residue of PCS sample is $0 \%$, implying that $\mathrm{MgO} / \mathrm{CoO}$ has been completely removed from PCS. Three PCS- $\mathrm{MnO}_{2}$ samples with different amounts of $\mathrm{MnO}_{2}$ are clearly shown in Supplementary Figure S2. It is worth noting that the sample of $\mathrm{PCS}-\mathrm{MnO}_{2}$ begins to lose weight before $300{ }^{\circ} \mathrm{C}$, which is due to the release of water trapped in the sample [35]. The weight loss in the range of $300 \sim 450{ }^{\circ} \mathrm{C}$ is due to the oxidation of PCS. In addition, due to chemical reaction of $\mathrm{MnO}_{2}$ to $\mathrm{Mn}_{2} \mathrm{O}_{3}$, a weak weight loss is also found after $450{ }^{\circ} \mathrm{C}$ [36]. Figure $3 \mathrm{~b}$ presents the Raman spectra of CP, PCS and $\mathrm{PCS}-\mathrm{MnO}_{2}-2$, respectively. All of them show two typical peaks at $1340 \mathrm{~cm}^{-1}$ and $1590 \mathrm{~cm}^{-1}$. The $\mathrm{D}$ band at $1340 \mathrm{~cm}^{-1}$ is related to the disordered vibration peak of amorphous carbon, and the $\mathrm{G}$ band at $1590 \mathrm{~cm}^{-1}$ corresponds to the ordered carbon [37]. The ratio of $\mathrm{I}_{\mathrm{D}} / \mathrm{I}_{\mathrm{G}}$ is used to estimate the graphitization degree of the carbon material. The higher $\mathrm{I}_{\mathrm{D}} / \mathrm{I}_{\mathrm{G}}$ ratio implies the lower graphitization degree. According to calculation, the $\mathrm{I}_{\mathrm{D}} / \mathrm{I}_{\mathrm{G}}$ value of $\mathrm{CP}$ and PCS is 1.12 and 0.99 , respectively. The lower 
$\mathrm{I}_{\mathrm{D}} / \mathrm{I}_{\mathrm{G}}$ value indicates that the porous structure of PCS has a higher graphitization degree with respect to $\mathrm{CP}$ due to the existence of $\mathrm{CoO}$ inducing a higher graphitization degree. After loading of $\mathrm{MnO}_{2}$ on PCS, the $\mathrm{I}_{\mathrm{D}} / \mathrm{I}_{\mathrm{G}}$ value of PCS- $\mathrm{MnO}_{2}-2$ slightly increases to 1.06 , implying that the graphitization degree decreased. At the same time, two new weak peaks at $569 \mathrm{~cm}^{-1}$ and $641 \mathrm{~cm}^{-1}$ appear which correspond to $\delta-\mathrm{MnO}_{2}$ in PCS-MnO $2-2$. This is consistent with the XRD result [38].

XPS analysis was used to investigate the surface chemical state of each element in the carbon samples. Supplementary Figure S3 shows XPS spectra of PCS-before $\mathrm{HCl}$ treatment, PCS, $\mathrm{PCS}-\mathrm{MnO}_{2}-2$ (a), and the narrow spectra of $\mathrm{Mn}_{2 p}$ peaks of the PCS- $\mathrm{MnO}_{2}-2$ (b). Supplementary Figure S3b shows high-resolution spectrum of Mn2p with the peaks at $653.8 \mathrm{eV}$ and $642.2 \mathrm{eV}$ corresponding to the $M n 2 p_{1 / 2}$ and $M n 2 p_{3 / 2}$, respectively. Moreover, the energy band of $11.6 \mathrm{eV}$ between Mn2p peaks indicates the presence of $\delta-\mathrm{MnO}_{2}$, which is also in agreement with the XRD and EDX mapping results [39]. Figure 4a displays the $\mathrm{N}_{2}$ adsorption/desorption isotherms of PCS and PCS- $\mathrm{MnO}_{2}$ composites, respectively. Based on IUPAC specifications, lower $\mathrm{N}_{2}$ adsorption at low relative pressure $\left(\mathrm{P} / \mathrm{P}_{0}<0.05\right)$ and adsorption at high relative pressure $\left(\mathrm{P} / \mathrm{P}_{0}>0.9\right)$ meet IV adsorption isotherm for two curves, indicating the abundant micropores and mesopores existed [40]. Meanwhile, the hysteresis loop in the curves also indicates the existence of mesopores. The above results are consistent with the pore size distribution analysis (Figure $4 \mathrm{~b}$ ). Figure $4 \mathrm{~b}$ shows the numerous mesopores that exist in the PCS, which is beneficial for the ions and electrolytes free transportation within the pores. The specific surface area of PCS and PCS- $\mathrm{MnO}_{2}-x(x=1,2,4)$ is reduced from $561 \mathrm{~m}^{2} \mathrm{~g}^{-1}$ to $453 \mathrm{~m}^{2} \mathrm{~g}^{-1}$, and the total pore volumes are $2.4 \mathrm{~cm}^{3} \mathrm{~g}^{-1}, 2.32 \mathrm{~cm}^{3} \mathrm{~g}^{-1}, 2.16 \mathrm{~cm}^{3} \mathrm{~g}^{-1}$, and $1.86 \mathrm{~cm}^{3} \mathrm{~g}^{-1}$, respectively. This means that the specific surface area and pore volume of $\mathrm{PCS}-\mathrm{MnO}_{2}$ composites decrease along with the increase in the amount of $\mathrm{MnO}_{2}$ loading. An appropriate amount of $\mathrm{MnO}_{2}$ loaded on PCS can not only introduce higher pseudo-capacitance to the material but also maintain a larger specific surface area and suitable pore structure, which endows the PCS- $\mathrm{MnO}_{2}$ composite based electrode with better electrochemical performance.
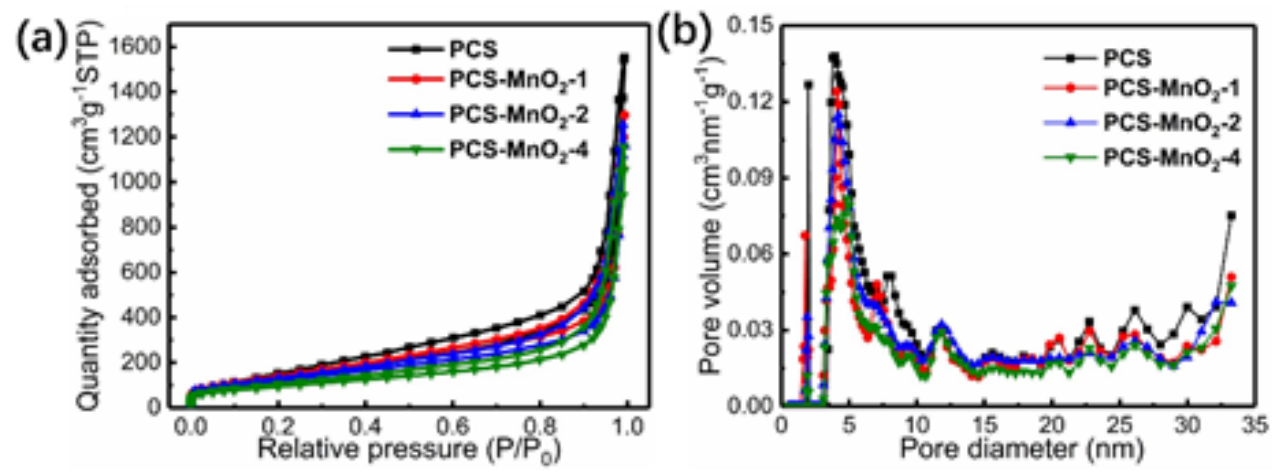

Figure 4. (a) $\mathrm{N}_{2}$ adsorption/desorption isotherms and (b) Pore size distributions of PCS and PCS-MnO 2 composites, respectively.

A three-electrode system was first applied to investigate the electrochemical properties of the prepared carbon samples. In Figure $5 \mathrm{a}$, the cyclic voltammetry $(\mathrm{CV})$ curves of PCS and PCS- $\mathrm{MnO}_{2}$ composites at $1 \mathrm{mV} \mathrm{s}^{-1}$ are shown. The rectangular-like CV curve of PCS proves its typical electric-double-layer behavior. For PCS- $\mathrm{MnO}_{2}$ composites, there are two obvious reduction peaks from $-0.4 \mathrm{~V}$ to $-0.1 \mathrm{~V}$, and another two obvious oxidation peaks in the range of $-0.7 \mathrm{~V}$ and $-0.4 \mathrm{~V}$. According to previous reports, the reduction peak around $-0.4 \mathrm{~V}$ and $-0.1 \mathrm{~V}$ is due to the reversible redox reaction between $\mathrm{Mn}$ (IV) and Mn (III). While another two oxidation peaks are attributed to the oxidation reaction between $\mathrm{Mn}$ (III) and $\mathrm{Mn}$ (II) [41]. In addition, the CV integral area of PCS- $\mathrm{MnO}_{2}-2$ is much larger than that of PCS and other PCS- $\mathrm{MnO}_{2}$ composites. The gravimetric capacitance reaches up to $193.8 \mathrm{~F} \mathrm{~g}^{-1}$ at $1 \mathrm{mV} \mathrm{s}^{-1}$, which is demonstrating that appropriate $\mathrm{MnO}_{2}$ loading can introduce pseudo-capacitance while maintaining a large specific surface area and suitable pore structure to 
improve the electrochemical performance of electrode materials. The corresponding GCD test at a current density of $1 \mathrm{~A} \mathrm{~g}^{-1}$ is presented in Figure 5b. Similarly, nearly triangle shape of PCS illustrates the electrochemical behavior of the electric double layer. For PCS-MnO 2 composites, there are two potential plateaus at $-0.4 \sim-0.1 \mathrm{~V}$ and $-0.7 \sim-0.4 \mathrm{~V}$, which are consistent with the $\mathrm{CV}$ curves and correspond to reversible redox reaction of the transition of $\mathrm{Mn}$ (IV) and $\mathrm{Mn}$ (III), and oxidation reactions of the transition of $\mathrm{Mn}$ (III) and Mn (II). Among these materials, PCS- $\mathrm{MnO}_{2}-2$ has the longest discharge time. As the loading of $\mathrm{MnO}_{2}$ increases, the discharge time of the $\mathrm{PCS}-\mathrm{MnO}_{2}$ composites firstly increases and then decreases. This is due to the accumulation of $\mathrm{MnO}_{2}$ in $\mathrm{PCS}-\mathrm{MnO}_{2}-2$, which reduces the utilization of $\mathrm{MnO}_{2}$ and the ion transportation rate. The CV curves of $\mathrm{PCS}-\mathrm{MnO}_{2}-2$ with the scan rate in the range of $1 \sim 200 \mathrm{mV} \mathrm{s}^{-1}$ are presented in Figure $5 \mathrm{c}$. The shape of the test curve remains the rectangular shape as the scan rate increases. Because of a larger specific area and suitable pore structure of PCS- $\mathrm{MnO}_{2}-2$ composite, it guarantees the channel opened and facilitates fast ions diffusion [42]. Figure $5 \mathrm{~d}$ shows the GCD results of $\mathrm{PCS}-\mathrm{MnO}_{2}-2$ at a current density of $1 \sim 20 \mathrm{~A} \mathrm{~g}^{-1}$. The gravimetric capacitance is as high as $210.5 \mathrm{~F} \mathrm{~g}^{-1}$ at $0.5 \mathrm{~A} \mathrm{~g}^{-1}$. At high current density, $\mathrm{PCS}-\mathrm{MnO}_{2}-2$ still shows quasi-triangular shape, which illustrates that $\mathrm{PCS}-\mathrm{MnO}_{2}-2$ has a good rate performance. Figure $5 \mathrm{e}$ shows the specific capacitance of PCS and PCS-MnO $\mathrm{O}_{2}$ composites at $1 \sim 20 \mathrm{~A} \mathrm{~g}^{-1}$. Under different current densities, the specific capacitance of $\mathrm{PCS}-\mathrm{MnO}_{2}-2$ always remains the highest in comparison to other electrode materials. It means that $\mathrm{PCS}-\mathrm{MnO}_{2}-2$ contains optimal $\mathrm{MnO}_{2}$ loading which maximizes the utilization of $\mathrm{MnO}_{2}$ while maintaining an appropriate pore structure. These features allowed to provide an excellent electrochemical performance of this sample. Figure $5 \mathrm{f}$ shows the areal capacitance of graphene, PCS, and PCS-MnO $\mathrm{Mn}_{2}-2$ at $1 \mathrm{mV} \mathrm{s}^{-1}$. It must be noted that the areal capacitance of PCS- $\mathrm{MnO}_{2}-2$ is as high as $0.33 \mathrm{~F} \mathrm{~m}^{-2}$, which is much higher than that of graphene $\left(0.21 \mathrm{~F} \mathrm{~m}^{-2}\right)$ due to the introduction of pseudocapacitive reactions.

The Nyquist plots were used to investigate the kinetic characteristics of ion diffusion in the tested electrode materials. As shown in Figure 6a, there are three parts in the above Nyquist plots, the intersection with the real axis in the high-frequency region corresponding to combined series resistance (Rs) of the materials. For PCS and three PCS- $\mathrm{MnO}_{2}$ composites, the Rs values are 2.08 ohm, $2.23 \mathrm{ohm}, 2.49 \mathrm{ohm}$ and $2.76 \mathrm{ohm}$, indicating that when more $\mathrm{MnO}_{2}$ is loaded on PCS, the intrinsic resistance correspondingly increases. In the mid-frequency region, the diameter of semicircle indicates the charge-transfer resistance (Rct) of the electrode materials [43]. The Rct of PCS and PCS-MnO 2 composites are $1.07 \mathrm{ohm}, 1.38 \mathrm{ohm}, 1.6 \mathrm{ohm}$, and $1.73 \mathrm{ohm}$, respectively. The increased amount of $\mathrm{MnO}_{2}$ on PCS reduces the pore width of the composite materials, and enlarges the distance of ion transportation, resulting in higher charge transportation resistance. In the low-frequency region, the curves become an inclined line and nearly vertical line indicates the good ion diffusion ability of electrode materials. To measure the ion diffusion resistance, the Warburg coefficient s (ohm s${ }^{-1 / 2}$ ) $\mathrm{can}$ be extracted by fitting the real part of impedance $\left(Z^{\prime}\right)$ versus the $-1 / 2$ power of the angular frequency $\left(\mathrm{w}^{-1 / 2}\right)$ in the low frequency range (Figure 6b) [44]. The slope of the fitted line equals the Warburg coefficient (s). The Warburg coefficient values of PCS and PCS- $\mathrm{MnO}_{2}$ composites are $0.33 \mathrm{ohm} \mathrm{s} \mathrm{m}^{-1 / 2}$, $0.69 \mathrm{ohm} \mathrm{s}^{-1 / 2}, 1.35 \mathrm{ohm} \mathrm{s}^{-1 / 2}$, and $1.97 \mathrm{ohm} \mathrm{s}^{-1 / 2}$, respectively. It is known that the Warburg coefficient is inversely proportional to the ion diffusion coefficient [45]. Therefore, it can be inferred from the Warburg coefficient and the change trend that abundant mesopores are beneficial for ion diffusion, and as the amount of loaded $\mathrm{MnO}_{2}$ increases, the difficulty of ion diffusion increases. Therefore, PCS- $\mathrm{MnO}_{2}-2$ loaded with a suitable amount of $\mathrm{MnO}_{2}$, can maintain a suitable porous characteristic while introducing pseudo-capacitance and displays high capacitances and excellent rate capabilities. Figure 6c shows that the specific capacitance still has a retention rate of $90.1 \%$ over 5000 times GCD cycles at a current density of $10 \mathrm{~A} \mathrm{~g}^{-1}$, the value is higher than those of PET-derived carbon materials previously reported (Supplementary Table S1) [46,47], which demonstrates the excellent cyclic stability of PCS- $\mathrm{MnO}_{2}-2$ composite. 
(a)

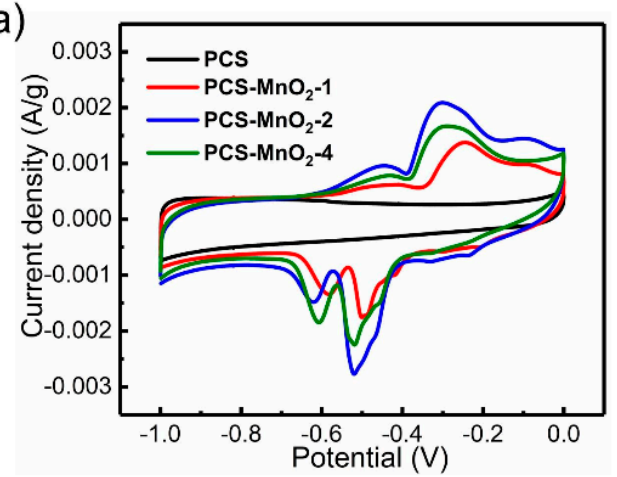

(c)

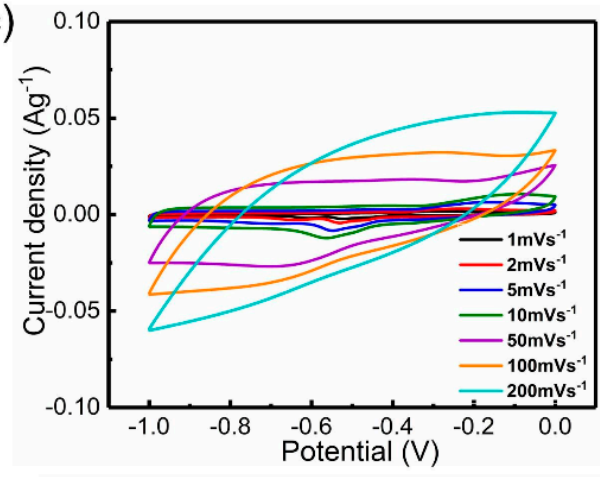

(e)

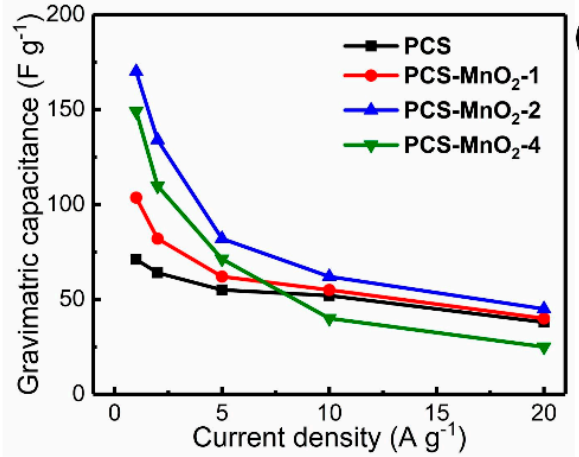

(b)

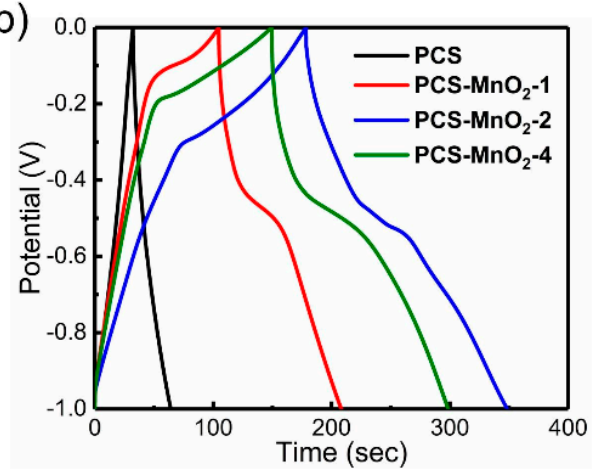

(d)
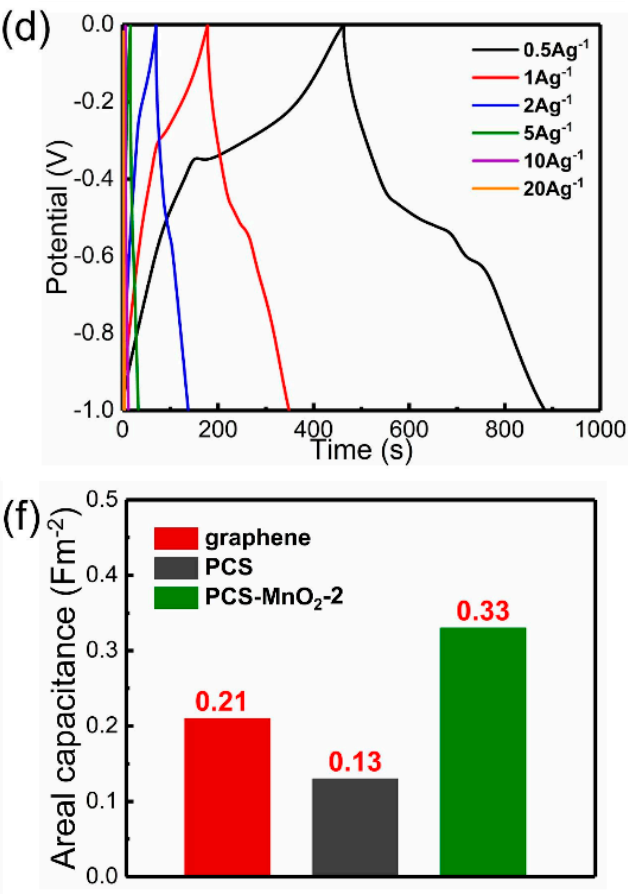

Figure 5. Electrochemical performance of PCS, $\mathrm{PCS}-\mathrm{MnO}_{2}$ composites in $6 \mathrm{M} \mathrm{KOH}$ electrolyte in the three-electrode test system: (a) CV curves tested at a scan rate of $1 \mathrm{mV} \mathrm{s}^{-1}$, (b) GCD curves tested at the current density of $1 \mathrm{~A} \mathrm{~g}^{-1}$. (c) CV curves of PCS-MnO ${ }_{2}-2$ at the scan rate in the range of $1 \sim 200 \mathrm{mV} \mathrm{s}^{-1}$, (d) GCD curves of PCS- $\mathrm{MnO}_{2}$ at the current density in the range of $0.5 \sim 20 \mathrm{~A} \mathrm{~g}^{-1}$. (e) The specific capacitance of PCS, PCS-MnO $\mathrm{Mn}_{2}$ composites at the current density in the range of $1 \sim 20 \mathrm{~A} \mathrm{~g}^{-1}$. (f) The areal capacitance of graphene, PCS and PCS- $\mathrm{MnO}_{2}-2$ at a scan rate of $1 \mathrm{mV} \mathrm{s}^{-1}$.

(a)

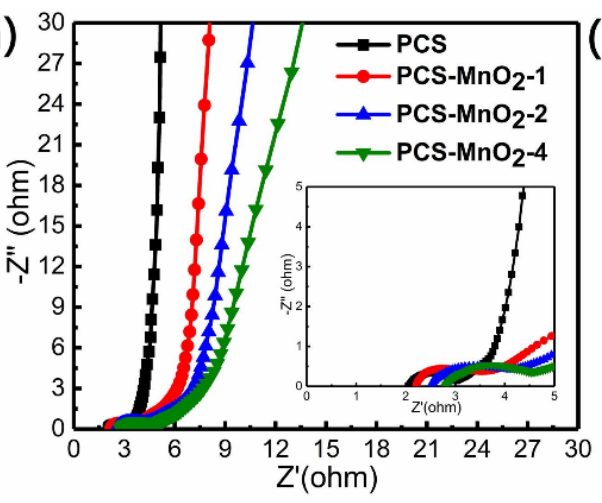

(b)

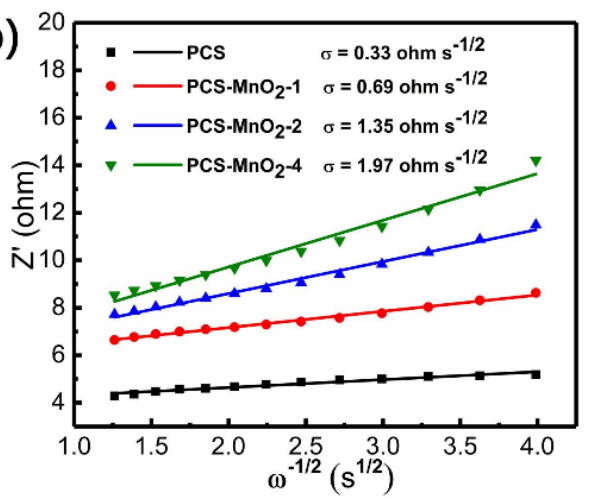

Figure 6. Cont. 


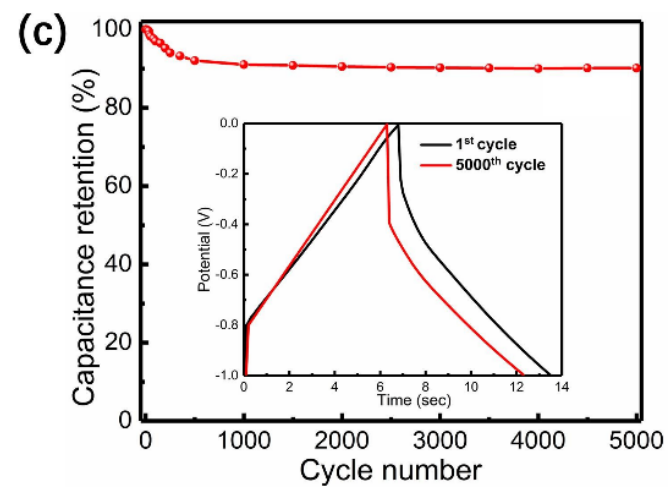

Figure 6. (a) The nyquist plots of PCS and PCS-MnO $2-x(x=1,2,4)$ composites (inset: magnified semicircular part) (b) Linear fitting to the real part of impedance $\left(Z^{\prime}\right)$ versus the $-1 / 2$ power of the angular frequency $\left(\mathrm{w}^{-1 / 2}\right)$ plots in a frequency range of $0.01 \mathrm{~Hz}$ to $0.1 \mathrm{~Hz}$ to estimate the ion diffusion resistance $(\sigma)$ of PCS and PCS-MnO ${ }_{2}$ composites. (c) The cycling performance at $10 \mathrm{~A} \mathrm{~g}^{-1}$ of PCS- $\mathrm{MnO}_{2}-2$ (inset: comparison of the first and the last charging-discharging cycle in cyclic stability test).

\section{Conclusions}

In summary, with the use of $\mathrm{MgO} / \mathrm{Co}(\mathrm{acac})_{3}$ as a template and catalyst, waste PET plastic was selectively carbonized into 3D porous carbon nanosheets with a high yield (36.4 wt\%). After loading uniform $\mathrm{MnO}_{2}$ nanoflakes on carbon nanosheets through a redox reaction, the as-prepared $\mathrm{PCS}-\mathrm{MnO}_{2}-2$ composite exhibited excellent capacitive performance in a supercapacitor. Due to the high specific surface area, appropriate pore size distribution, and uniformly distributed $\mathrm{MnO}_{2}$ active sites, the PCS- $\mathrm{MnO}_{2}-2$ composite delivered a gravimetric capacitance of $210.5 \mathrm{~F} \mathrm{~g}^{-1}$ and areal capacitance of $0.33 \mathrm{~F} \mathrm{~m}^{-2}$, as well as excellent cycle stability. The present work demonstrates a strategy for the one-step carbonization of PET waste plastics into PCSs for energy storage, achieving the goal of recycling plastic waste into a high value-added product.

Supplementary Materials: The following are available online at http:/www.mdpi.com/2079-4991/10/6/1097/s1, Figure S1. (a) SEM of PCS-MnO2-2; EDX Mapping of (b) CK $\alpha 1$ (c) OK $\alpha 1$ (d) MnK $\alpha 1$; Figure S2. TGA curves of PCS-before pickling, PCS, and PCS- $\mathrm{MnO}_{2}$ composites; Figure S3. XPS survey spectra of (a) PCS-before pickling, PCS, and PCS- $\mathrm{MnO}_{2}-2$; (b)the narrow spectra of $\mathrm{Mn}_{2 \mathrm{p}}$ peaks of the $\mathrm{PCS}-\mathrm{MnO}_{2}-2$. Table S1. Comparison of the capacitance retention of carbon materials in the literature.

Author Contributions: X.C. designed the experiments. X.L., C.M. and H.J. administered the experiments. X.M. performed experiments. Y.L., T.T., E.M. and J.Z. gave conceptual advice. All authors analyzed and discussed the data and wrote the manuscript. All authors have read and agree to the published version of the manuscript.

Funding: This research was funded by and National Science Centre, Poland within BEETHOVEN UMO-2016/23/G/ST5/04200 and the Open Project of State Key Laboratory Cultivation Base for Nonmetal Composites and Functional Materials (grant no. 17kffk02), the Project of State Key Laboratory of Environment-friendly Energy Materials, Southwest University of Science and Technology (grant no. 18fksy0221).

Conflicts of Interest: The authors declare no conflict of interest.

\section{References}

1. Mangesh, V.L.; Padmanabhan, S.; Tamizhdurai, P.; Ramesh, A. Experimental investigation to identify the type of waste plastic pyrolysis oil suitable for conversion to diesel engine fuel. J. Clean. Prod. 2020, 246, 119066. [CrossRef]

2. Le, D.K.; Leung, R.I.H.; Er, A.S.R.; Zhang, X.W.; Tay, X.J.; Thai, Q.B.; Nhan, P.T.; Duong, H.M. Applications of functionalized polyethylene terephthalate aerogels from plastic bottle waste. Waste Manag. 2019, 100, $296-305$. [CrossRef] [PubMed]

3. Wong, S.L.; Ngadi, N.; Abdullah, T.A.T.; Inuwa, I.M. Current state and future prospects of plastic waste as source of fuel: A review. Renew. Sustain. Energy Rev. 2015, 50, 1167-1180. [CrossRef] 
4. Geyer, R.; Jambeck, J.R.; Law, K.L. Production, use, and fate of all plastics ever made. Sci. Adv. 2017, 3, 1700782. [CrossRef] [PubMed]

5. Hahladakis, J.N.; Iacovidou, E. An overview of the challenges and trade-offs in closing the loop of post-consumer plastic waste (PCPW): Focus on recycling. J. Hazard. Mater. 2019, 380, 120887. [CrossRef]

6. Elessawy, N.A.; Elnouby, M.; Gouda, M.H.; Hamad, H.A.; Taha, N.A.; Gouda, M.; Eldin, M.S.M. Ciprofloxacin removal using magnetic fullerene nanocomposite obtained from sustainable PET bottle wastes: Adsorption process optimization, kinetics, isotherm, regeneration and recycling studies. Chemosphere 2020, 239, 124728. [CrossRef]

7. Chen, X.; He, J.; Yan, C.; Tang, H. Novel in situ fabrication of chestnut-like carbon nanotube spheres from polypropylene and nickel formate. J. Phys. Chem. B 2006, 110, 21684-21689. [CrossRef]

8. Gong, J.; Chen, X.; Tang, T. Recent progress in controlled carbonization of (waste) polymers. Prog. Polym. Sci. 2019, 94, 1-32. [CrossRef]

9. Zhang, S.; Shi, X.; Wrobel, R.; Chen, X.; Mijowska, E. Low-cost nitrogen-doped activated carbon prepared by polyethylenimine (PEI) with a convenient method for supercapacitor application. Electrochim. Acta 2019, 294, 183-191. [CrossRef]

10. Wen, Y.; Zhang, L.; Liu, J.; Wen, X.; Chen, X.; Ma, J.; Tang, T.; Mijowska, E. Hierarchical porous carbon sheets derived on a $\mathrm{MgO}$ template for high-performance supercapacitor applications. Nanotechnology 2019, 30, 295703. [CrossRef]

11. Liu, X.; Ma, C.; Li, J.; Zielinska, B.; Kalenczuk, J.R.; Chen, X.; Chu, P.; Tang, T.; Mijowska, E. Biomass-derived robust three-dimensional porous carbon for high volumetric performance supercapacitors. J. Power Sources 2019, 412, 1-9. [CrossRef]

12. Liu, X.; Wen, Y.; Chen, X.; Tang, T.; Mijowska, E. Co-etching effect to convert waste polyethylene terephthalate into hierarchical porous carbon toward excellent capacitive energy storage. Sci. Total Environ. 2020, 723, 138055. [CrossRef] [PubMed]

13. Lopez, F.R.; Duque, I.I.; de Rivas, B.; Arnaiz, S.; Gutierrez, O.J.I. Chemical recycling of post-consumer PET wastes by glycolysis in the presence of metal salts. Polym. Degrad. Stabil. 2010, 95, 1022-1028. [CrossRef]

14. Ingrao, C.; Giudice, A.L.; Tricase, C.; Rana, R.; Mbohwa, C.; Siracusa, V. Recycled-PET fiber based panels for building thermal insulation: Environmental impact and improvement potential assessment for a greener production. Sci. Total Environ. 2014, 493, 914-929. [CrossRef] [PubMed]

15. Ahmadinia, E.; Zargar, M.M.; Karim, R.; Abdelaziz, M.; Ahmadinia, E. Performance evaluation of utilization of waste Polyethylene Terephthalate (PET) in stone mastic asphalt. Constr. Build. Mater. 2012, 36, 984-989. [CrossRef]

16. Elessawy, N.A.; El Nady, J.; Wazeer, W.; Kashyout, A.B. Development of High-Performance Supercapacitor based on a Novel Controllable Green Synthesis for 3D Nitrogen Doped Graphene. Sci. Rep. 2019, 9, 1129. [CrossRef]

17. Kamali, A.R.; Yang, J.G.; Sun, Q. Molten salt conversion of polyethylene terephthalate waste into graphene nanostructures with high surface area and ultra-high electrical conductivity. Appl. Surf. Sci. 2019, 476, 539-551. [CrossRef]

18. Chen, T.Y.; Vedhanarayanan, B.; Lin, S.Y.; Shao, L.D.; Sofer, Z.; Lin, J.Y.; Lin, T.W. Electrodeposited NiSe on a forest of carbon nanotubes as a free-standing electrode for hybrid supercapacitors and overall water splitting. J. Colloid Interface Sci. 2020, 574, 300-311. [CrossRef]

19. Shi, X.; Zhang, S.; Chen, X.; Tang, T.; Mijowska, E. Three dimensional graphene/carbonized metal-organic frameworks based high-performance supercapacitor. Carbon 2020, 157, 55-63. [CrossRef]

20. Zhang, S.; Shi, X.; Moszynski, D.; Tang, T.; Chu, P.K.; Chen, X.; Ewa Mijowska, E. Hierarchical porous carbon materials from nanosized metal-organic complex for high-performance symmetrical supercapacitor. Electrochim. Acta 2018, 269, 580-589. [CrossRef]

21. Ehsani, A.A.; Heidari, A.; Shiri, H.M. Electrochemical Pseudocapacitors Based on Ternary Nanocomposite of Conductive Polymer/Graphene/Metal Oxide: An Introduction and Review to it in Recent Studies. Chem. Rec. 2019, 19, 908-926. [CrossRef] [PubMed]

22. Zhai, Y.; Dou, Y.; Zhao, D.; Fulvio, P.F.; Mayes, R.T.; Dai, S. Carbon materials for chemical capacitive energy storage. Adv. Mater. 2011, 23, 4828-4850. [CrossRef] [PubMed]

23. Chen, X.; Wang, H.; He, J. Synthesis of carbon nanotubes and nanospheres with controlled morphology using different catalyst precursors. Nanotechnology 2008, 19, 325607. [CrossRef] [PubMed] 
24. Cakici, M.; Reddy, K.R.; Marroquin, F.A. Advanced electrochemical energy storage supercapacitors based on the flexible carbon fiber fabric-coated with uniform coral-like $\mathrm{MnO}_{2}$ structured electrodes. Chem. Eng. J. 2017, 309, 151-158. [CrossRef]

25. Song, M.; Zhou, Y.; Ren, X.; Wan, F.; Du, Y.; Wu, G.; Ma, F. Biowaste-based porous carbon for supercapacitor: The influence of preparation processes on structure and performance. J. Colloid Interface Sci. 2019, 535, 276-286. [CrossRef] [PubMed]

26. Dong, Y.; Zhang, S.; Du, X.; Hong, S.; Zhao, S.N.; Chen, Y.; Chen, X. Boosting the Electrical Double-Layer Capacitance of Graphene by Self-Doped Defects through Ball-Milling. Adv. Funct. Mater. 2019, 29, 1901127. [CrossRef]

27. Vouvoudi, E.C.; Achilias, D.S. Pyrolytic degradation of common polymers present in packaging materials. J. Therm. Anal. Calorim. 2019, 138, 2683-2689. [CrossRef]

28. Mattevi, C.; Kim, H.; Chhowalla, M. A review of chemical vapor deposition of graphene on copper. J. Mater. Chem. 2011, 21, 3324-3334. [CrossRef]

29. Ma, C.; Liu, X.; Min, J.; Li, J.; Gong, J.; Wen, X.; Chen, X.; Tang, T.; Mijowska, E. Sustainable recycling of waste polystyrene into hierarchical porous carbon nanosheets with potential applications in supercapacitors. Nanotechnology 2020, 31, 035402. [CrossRef]

30. Liu, T.; Zhou, Z.; Guo, Y.; Guo, D.; Liu, G. Block copolymer derived uniform mesopores enable ultrafast electron and ion transport at high mass loadings. Nat. Commun. 2019, 10, 675. [CrossRef]

31. Sun, H.; Gu, H.; Zhang, L.; Chen, Y. Redox deposition of birnessite $\mathrm{MnO}_{2}$ on ZIF-8 derived porous carbon at room temperature for supercapacitor electrodes. Mater. Lett. 2018, 216, 123-126. [CrossRef]

32. Hong, N.; Tang, G.; Wang, X.; Hu, W.; Song, L.; Hu, Y. Selective preparation of carbon nanoflakes, carbon nanospheres, and carbon nanotubes through carbonization of polymethacrylate by using different catalyst precursors. J. Appl. Polym. Sci. 2013, 130, 1029-1037. [CrossRef]

33. Hou, J.; Cao, C.; Idrees, F.X.; Ma, L. Hierarchical Porous Nitrogen-Doped Carbon Nanosheets Derived from Silk for Ultrahigh-Capacity Battery Anodes and Supercapacitors. ACS Nano 2015, 9, 2556-2564. [CrossRef] [PubMed]

34. Zhu, X.; Dai, Y.; Sun, Y.; Liu, H.; Sun, W.; Lin, Y.; Gao, D.; Han, R.; Wang, X.; Luo, C. Rapid fabrication of electrode for the detection of alpha fetoprotein based on $\mathrm{MnO}_{2}$ functionalized mesoporous carbon hollow sphere. Mater. Sci. Eng. C Mater. 2020, 107, 110206. [CrossRef] [PubMed]

35. Yumak, T.; Bragg, D.; Sabolsky, E.M. Effect of synthesis methods on the surface and electrochemical characteristics of metal oxide/activated carbon composites for supercapacitor applications. Appl. Surf. Sci. 2019, 469, 983-993. [CrossRef]

36. Liu, Y.H.; Hsi, H.C.; Li, K.C.; Hou, C.H. Electrodeposited Manganese Dioxide/Activated Carbon Composite as a High-Performance Electrode Material for Capacitive Deionization. ACS Sustain. Chem. Eng. 2016, 4, 4762-4770. [CrossRef]

37. Yan, J.; Fan, Z.; Wei, T.; Qian, W.; Zhang, M.; Wei, F. Fast and reversible surface redox reaction of graphene- $\mathrm{MnO}_{2}$ composites as supercapacitor electrodes. Carbon 2010, 48, 3825-3833. [CrossRef]

38. Han, Z.; Wang, C.; Zou, X.; Chen, T.; Dong, S.; Zhao, Y.; Xie, J.; Liu, H. Diatomite-supported birnessite-type $\mathrm{MnO}_{2}$ catalytic oxidation of formaldehyde: Preparation, performance and mechanism. Appl. Surf. Sci. 2020, 502, 144201. [CrossRef]

39. Jabeen, N.; Xia, Q.Y.; Savilov, S.V.; Aldoshin, S.M.; Yu, Y.; Xia, H. Enhanced Pseudocapacitive Performance of alpha- $\mathrm{MnO}_{2}$ by Cation Preinsertion. ACS Appl. Mater. Interfaces 2016, 8, 33732-33740. [CrossRef]

40. Min, J.; Zhang, S.; Li, J.; Klingeler, R.; Wen, X.; Chen, X.; Zhao, X.; Tang, T.; Mijowska, E. From polystyrene waste to porous carbon flake and potential application in supercapacitor. Waste Manag. 2019, 85, 333-340. [CrossRef]

41. Xie, Y.; Yang, C.; Chen, P.; Yuan, D.; Guo, K. $\mathrm{MnO}_{2}$-decorated hierarchical porous carbon composites for high-performance asymmetric supercapacitors. J. Power Sources 2019, 425, 1-9. [CrossRef]

42. Ghasemi, S.; Hosseini, S.R.; Boore-talari, O. Sonochemical assisted synthesis $\mathrm{MnO}_{2} / \mathrm{RGO}$ nanohybrid as effective electrode material for supercapacitor. Ultrason. Sonochem. 2018, 40, 675-685. [CrossRef] [PubMed]

43. Hu, L.; Hou, J.; Ma, Y.; Li, H.; Zhai, T. Multi-heteroatom self-doped porous carbon derived from swim bladders for large capacitance supercapacitors. J. Mater. Chem. A 2016, 4, 15006-15014. [CrossRef] 
44. Yuan, Y.; Zhan, C.; He, K.; Chen, H.; Yao, W.; Sharifi-Asl, S.; Song, B.; Yang, Z.; Nie, A.; Luo, X.; et al. The influence of large cations on the electrochemical properties of tunnel-structured metal oxides. Nat. Commun. 2016, 7, 13374. [CrossRef] [PubMed]

45. Yu, J.; Yu, C.; Guo, W.; Wang, Z.; Li, S.; Chang, J.; Tan, X.; Ding, Y.; Zhang, M.; Yang, L.; et al. Decoupling and correlating the ion transport by engineering 2D carbon nanosheets for enhanced charge storage. Nano Energy 2019, 64, 103921. [CrossRef]

46. Wen, Y.; Kierzek, K.; Chen, X.; Gong, J.; Liu, J.; Niu, R.; Mijowska, E.; Tang, T. Mass production of hierarchically porous carbon nanosheets by carbonizing "real-world" mixed waste plastics toward excellent-performance supercapacitors. Waste Manag. 2019, 87, 691-700. [CrossRef]

47. Domingo-Garcia, M.; Fernandez, J.A.; Almazan-Almazan, M.C.; Lopez-Garzon, F.J.; Stoeckli, F.; Centeno, T.A. Poly(ethylene terephthalate)-based carbons as electrode material in supercapacitors. J. Power Sources 2010, 195, 3810-3813. [CrossRef]

(C) 2020 by the authors. Licensee MDPI, Basel, Switzerland. This article is an open access article distributed under the terms and conditions of the Creative Commons Attribution (CC BY) license (http://creativecommons.org/licenses/by/4.0/). 